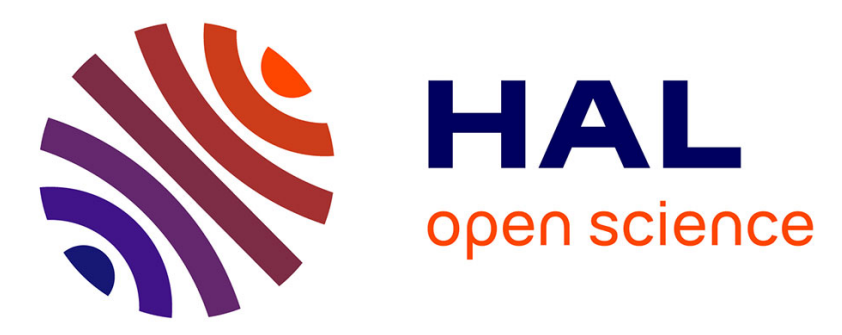

\title{
Uncertainty Quantification in the Assessment of Human Exposure near Wireless Power Transfer Systems in Automotive Applications
}

Paul Lagouanelle, Van-Lang Krauth, Lionel Pichon

\section{- To cite this version:}

Paul Lagouanelle, Van-Lang Krauth, Lionel Pichon. Uncertainty Quantification in the Assessment of Human Exposure near Wireless Power Transfer Systems in Automotive Applications. AEIT AUTOMOTIVE 2019, Jul 2019, Turin, Italy. 10.23919/EETA.2019.8804593 hal-02333919

\section{HAL Id: hal-02333919 https://hal.science/hal-02333919}

Submitted on 19 Aug 2020

HAL is a multi-disciplinary open access archive for the deposit and dissemination of scientific research documents, whether they are published or not. The documents may come from teaching and research institutions in France or abroad, or from public or private research centers.
L'archive ouverte pluridisciplinaire $\mathbf{H A L}$, est destinée au dépôt et à la diffusion de documents scientifiques de niveau recherche, publiés ou non, émanant des établissements d'enseignement et de recherche français ou étrangers, des laboratoires publics ou privés. 


\title{
Uncertainty Quantification in the Assessment of Human Exposure near Wireless Power Transfer Systems in Automotive Applications
}

\author{
Paul Lagouanelle, Van-Lang Krauth, Lionel Pichon \\ GeePs | Group of electrical engineering - Paris, CNRS, CentraleSupélec, Univ. Paris-Sud, Université Paris-Saclay, Sorbonne Université, \\ 3 \& 11 rue Joliot-Curie, 91192 Gif-sur-Yvette, France
}

\begin{abstract}
This paper addresses the uncertainty quantification of physical and geometrical material parameters in the design of wireless power transfer systems and in the assessment of the level of exposure for automotive applications. In a first step, Monte Carlo simulations are used to obtain the mean and confidence interval of the shielding effectiveness for conducting and composite materials over a wide frequency range in case of an academic shielding configuration. In a second step, a nonintrusive stochastics technique (Kriging) is combined with a 3D finite element method to study a simplified but realistic configuration of a power transfer system at $85 \mathrm{kHz}$. Such a prediction of uncertainties may help in the design of shields for inductive power transfer systems which comply with health and safety standards.
\end{abstract}

Keywords-EMC, Shielding effectiveness, Wireless power transfer, Uncertainty quantification

\section{INTRODUCTION}

In recent years, inductive power transfer (IPT) systems have been widely developed in several fields such as biomedical engineering, consumer electronics and the automotive industry. With such increased use, human exposure to the electromagnetic fields radiated by these systems in day to day life must be thorougly investigated. The coupling between the transmitter, placed on the ground, and the receiver, placed under the vehicle floor, occurs through a large air-gap. This large gap implies a high level of stray field near the coils, that may represent a problem in terms of exposure to magnetic fields for passengers or people close to the vehicle during charging. It is therefore needed to design effective shielding materials to meet health and safety guidelines [1-4]. Furthermore, it is also important to evaluate the shielding effectiveness due to uncertainties in the electromagnetic and physical properties of a material; for instance, the electrical conductivity of new composite materials has a strong impact on the shielding effectiveness (SE) of sheets [5].

In order to assess human exposure near IPT systems in automotive applications, adequate modeling methodologies have to be developed. Nowadays 3D computational models are studied and applied to solve the electromagnetic problem involving the wireless system, the vehicle and the human body (in the vehicle or located beside) [3]. Such full wave computational approaches give reliable results about the radiated fields around the system or the induced quantities in the human body but may lead to heavy computations that must be repeated for each new configuration. A key point in such problems is that the level of exposure is highly dependent on various parameters: the shape or size of coils, the geometrical characteristics of the system (structural parts of the vehicle, shielding plates), materials properties (ferrite, chassis of vehicle), the possible misalignment between transmitter and receiver while charging, the position of the human body. Moreover, each physical or geometrical parameter may be affected by some uncertainty. Therefore during the design of the IPT system, the consideration of the level of exposure cannot only rely on deterministic full 3D solvers. In such a situation the introduction of stochastic tools allows us to deal with the variability of all the parameters describing the electromagnetic problem. Such approaches were shown to be very efficient in the framework of the determination of specific rate absorption (SAR) in biological tissues due to mobile phones at microwaves frequencies [6,7]. Preliminary work demonstrated the interest of these stochastics techniques in IPT systems and underlined that Kriging appears a fast and reliable tool in such problems [8].

This paper studies the uncertainty propagation parameters in the predictions of radiated magnetic fields for a range of frequencies dealing with wireless power transfer. The first case considers a source loop in a low frequency range of 0$100 \mathrm{kHz}$. Such standard geometry is a basic situation in IPT [9]. A Monte Carlo simulation [10] is then applied where a hundred tests were run at each frequency point. The mean of the results calculated is then plotted with the confidence interval against the frequency. Such study easily visualizes the uncertainties propagation effects on the shielding effectiveness in the case of different varying parameters. The second one involves a simplified but realistic inductive power transfer considered in [3]. With this configuration, Monte Carlo approaches are too costly, and a stochastic approach which only involves a limited set of samples provides a meta-model or surrogate model able to deal with the variability of the parameters. Kriging is also chosen due to its performances in electromagnetic compatibility problems.

\section{SHIELDING OF CIRCULAR COIL}

In the first electromagnetic problem, an analytical solution is available, and the shielding effectiveness is obtained at low cost. This allows us to achieve many calculations rapidly with a Monte Carlo simulation. The case of the circular loop has been studied in [11]. The model consists of a single planar shield lying in the $x-y$ plane, parallel to a 
current carrying loop also lying in the $\mathrm{x}-\mathrm{y}$ plane, with radius " $a$ " and centered at the origin. The shielding effectiveness is evaluated at some observation point along the $\mathrm{z}$ axis. Note that the distance between the shield and the observation point $\mathrm{Z}$ does not affect the value of the shielding effectiveness.

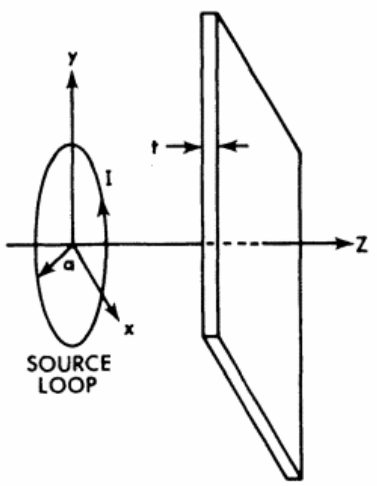

Fig. 1. Circular loop case [11]

The case of a $2 \mathrm{~mm}$ aluminum sheet with variable thickness (t) and conductivity is compared to the same system with a given thickness. The radius of the loop is $\mathrm{a}=$ $50 \mathrm{~mm}$ and $\mathrm{SE}$ is evaluated at $\mathrm{z}=100 \mathrm{~mm}$. The statistical properties are shown in Table I. Gaussian distributions are considered. While the mean of SE appears unaffected, figure 2 shows that a slight variance in the thickness results in a far larger standard deviation. This results in a confidence interval of SE which is approximately $10 \mathrm{~dB}$.

TABLE I

STATISTICAL PROPERTIES

\begin{tabular}{|c|c|c|}
\hline Input parameter & Mean & Standard deviation \\
\hline Thickness $(\mathrm{mm})$ & 2 & 0.1 \\
\hline Conductivity $(\mathrm{S} / \mathrm{m})$ & $3.8 \times 10^{7}$ & $7.4 \times 10^{5}$ \\
\hline
\end{tabular}

Table 1. Statistical properties of input variables (loop case)

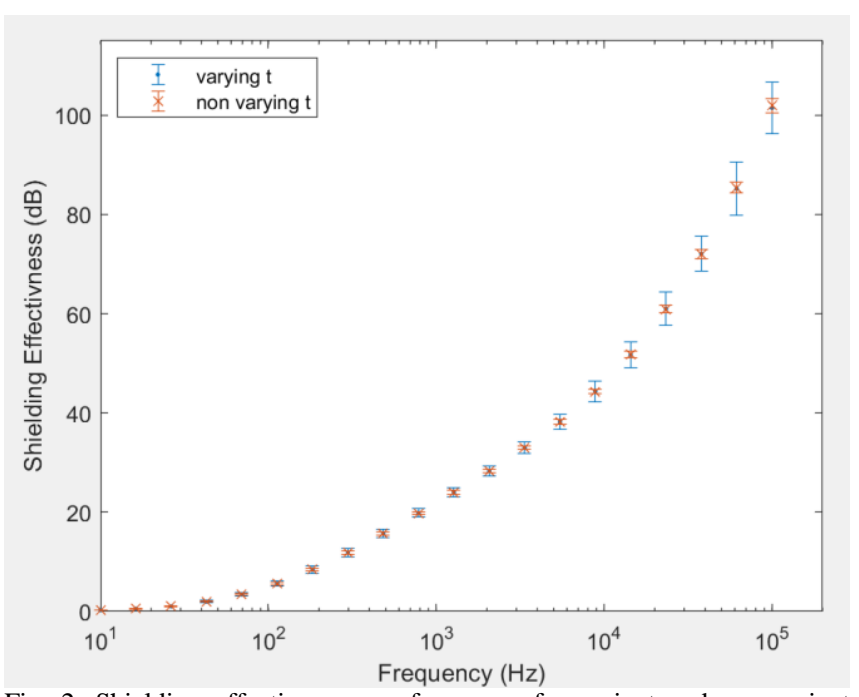

Fig. 2. Shielding effectiveness vs frequency for variant and non-variant thickness (t)

Such preliminary study is now expanded upon more complex systems using numerical electromagnetic models. Results will be presented at the conference.

\section{WIRELESS POWER CONFIGURATION}

\section{A. Studied configuration}

The structure model of the system considered in this work contains two rectangular coils (transmitter and receiver), and two ferrite plates $[1,3]$. The distance between the two coils is $0.25 \mathrm{~m}$. The design also includes a steel plate that represents the chassis of the electric vehicle (Fig. 3). Previous studies have shown that such a simplified chassis is sufficient to evaluate its impact on the results. The dimensions of the system are shown on table 2 .

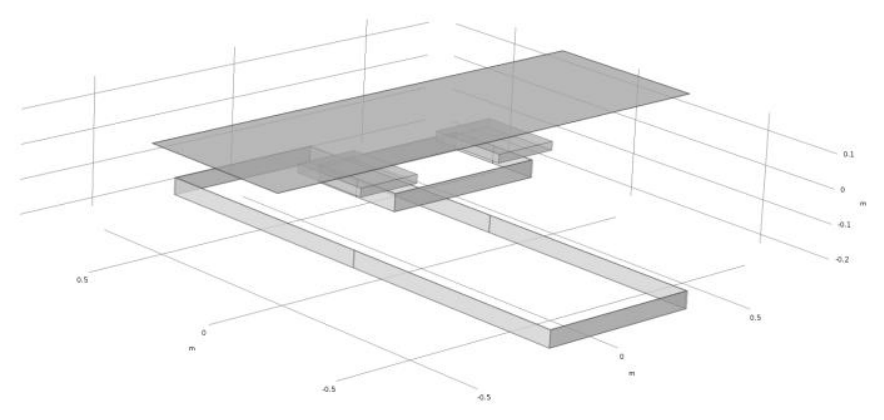

Fig. 3. Studied configuration of the wireless transfer system

\begin{tabular}{ccc}
\multicolumn{3}{c}{ TABLE II } \\
DIMENSIONS \\
\hline \hline Width $(\mathrm{m})$ & Length $(\mathrm{m})$ \\
\hline Transmitter & 0.5 & 1.5 \\
Receiver & 0.5 & 0.3 \\
Ferrite & 0.2 & 0.25 \\
Frame & 1.5 & 0.5 \\
\hline
\end{tabular}

Table 2. Dimensions of the wireless power transfer system

The relative permeability of ferrite is 2200. Each coil has 10 turns. The magneto-dynamic problem is solved with a 3D vector potential formulation. This system has been designed for dynamic charging but in the present work only a static charging is considered. The power electronics controls and keeps the rms value of the current in the transmitter at $36 \mathrm{~A}$ and the current in the receiver at $75 \mathrm{~A}$, respectively.

\section{B. Kriging}

Kriging is a stochastic interpolation algorithm which assumes that the model output $\mathrm{M}(\mathrm{x})$ is a realization of a Gaussian process indexed by the inputs x. A Kriging metamodel is described by the following equation [12]:

$M(x) \sim M^{K}(x)=\beta^{T} f(x)+\sigma^{2} Z(x, \omega)$

The first term in (1), is the mean value of the Gaussian process (trend) and it consists of the regression coefficients $\beta_{j}(j=1, \ldots P)$ and the basis functions $f_{j}(j=1, \ldots P)$. The second term in (1) consists of $\sigma^{2}$, the (constant) variance of the Gaussian process and $\mathrm{Z}(\mathrm{x}, \omega)$, a zero mean, unit 
variance, stationary Gaussian process. The underlying probability space is represented by $\omega$ and is defined in terms of a correlation function $\mathrm{R}$ and its hyper-parameters $\theta$ The correlation function $\mathrm{R}=\mathrm{R}\left(\mathrm{x} ; \mathrm{x}_{0} ; \theta\right)$ describes the correlation between two samples of the input space, e.g. $\mathrm{x}$ and $\mathrm{x}_{0}$ and depends on the hyperparameters $\theta$. In the context of metamodelling, it is of interest to calculate a prediction $\mathrm{M}^{\mathrm{K}}(\mathrm{x})$ for a new point $\mathrm{x}$, given $\mathrm{X}=\left(\mathrm{x}_{1}, \ldots \mathrm{x}_{\mathrm{n}}\right)$, the experimental design and $\mathrm{y}=\left(\mathrm{y}_{1}=\mathrm{M}\left(\mathrm{x}_{1}\right), \ldots, \mathrm{y}_{\mathrm{n}}=\mathrm{M}\left(\mathrm{x}_{\mathrm{n}}\right)\right)$, the corresponding (noise-free) model responses. A Kriging meta-model (Kriging predictor) provides such predictions based on the Gaussian properties of the process.

The meta-model described above and used in this paper was developed in [12] and proposed in the framework for uncertainty quantification freely available.

\section{NUMERICAL RESULTS AND DISCUSSION}

Kriging has been applied in the configuration of Fig. 3 . to check the compliance regarding the references levels of the radiated magnetic field. For the frequency of interest (85 $\mathrm{kHz}$ ), the maximum admissible value of the magnetic flux density is $27 \mu \mathrm{T}$ according to the ICNIRP Guidelines (2010).

\section{A. First case - 1 parameter (frame conductivity)}

In a first example, the uncertainty regarding the frame conductivity is investigated. The range of variation is shown in table III. It covers both the case of composite materials (with low conductivity) and standard conducting materials. The 3D finite element mesh includes between 80000 and 90000 elements. First order nodal elements are used in the method.

TABLE III

\begin{tabular}{l} 
PARAMETERS OF THE ELECTROMAGNETIC PROBLEM \\
\hline \begin{tabular}{ccc} 
Parameter & Min & Max \\
\hline$\sigma(\mathrm{S} / \mathrm{m})$ & $10^{4}$ & $10^{6}$ \\
\hline
\end{tabular}
\end{tabular}

Table 3. Range of variation of the parameter

In order to check the efficiency of the meta-models, a total number of 15 computations is performed by FEM (COMSOL) based on a uniform logarithmic distribution of samples over the whole range of variations. Fig. 5. shows the mean of the flux density and the confidence interval provided by the meta-model in a point located at $50 \mathrm{~cm}$ near the frame representing the possible location of a bystander (red point on Fig.4).

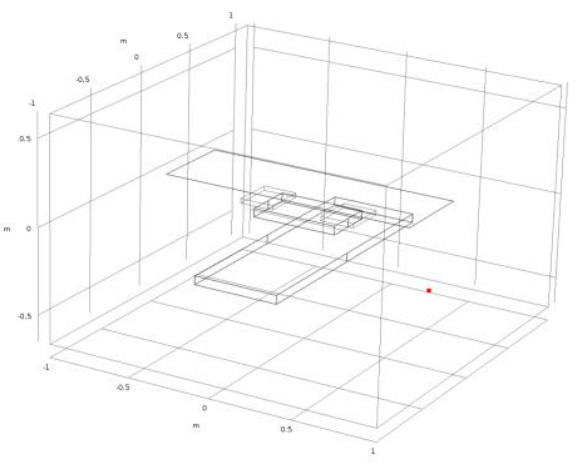

Fig. 4. Location of the observation point (red point)
The magnitude of the prediction is clearly exceeding the threshold $(27 \mu \mathrm{T})$. The accuracy of the meta-model is checked thanks to the LOO (leave-one-out) cross-validation provided by Kriging and defined according to [12]:

$$
E_{00}=\sum_{i=1}^{N}\left(M\left(x_{i}\right)-\mu_{\tilde{Y},(-i)}\left(x_{i}\right)\right)^{2} / \operatorname{Var}[Y]
$$

This quantity involves in each sampling point $x_{i}$ the error between the value provided by the model and the Kriging prediction by using all the sampling points except $\mathrm{x}_{\mathrm{i}}$.

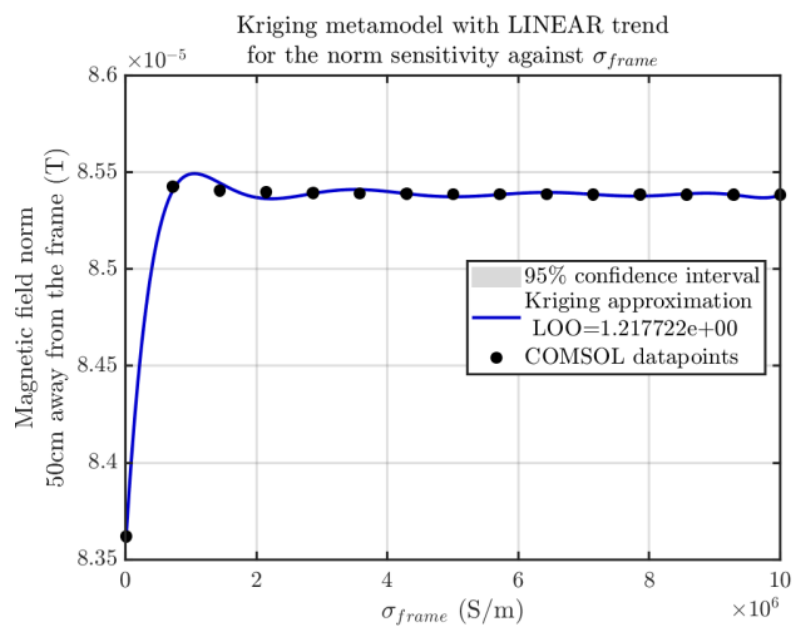

Fig. 5. Predictions of Kriging from the basis of 15 samples

\section{B. Second case - 2 parameters (frame conductivity and misalignment between emitter and receiver)}

In this second configuration the first parameter $\sigma$ is the same than in IV.A and the second parameter D is the distance between the two axes of the coils (Fig. 6). This configuration may appear in case of large misalignment or if the receiver is located in the rear of the vehicle. The range of variations of the two parameters is given on table IV.

TABLE IV

\begin{tabular}{ccc} 
PARAMETERS OF THE ELECTROMAGNETIC PROBLEM \\
\hline Parameter & Min & Max \\
\hline$\sigma(\mathrm{S} / \mathrm{m})$ & $10^{4}$ & $10^{6}$ \\
$\mathrm{D}(\mathrm{m})$ & 0. & 0.5 \\
\hline
\end{tabular}

Table 4. Range of variation of the parameter

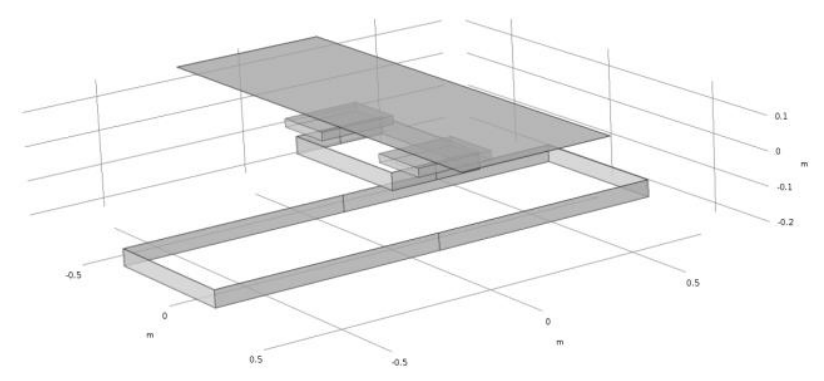

(a) 


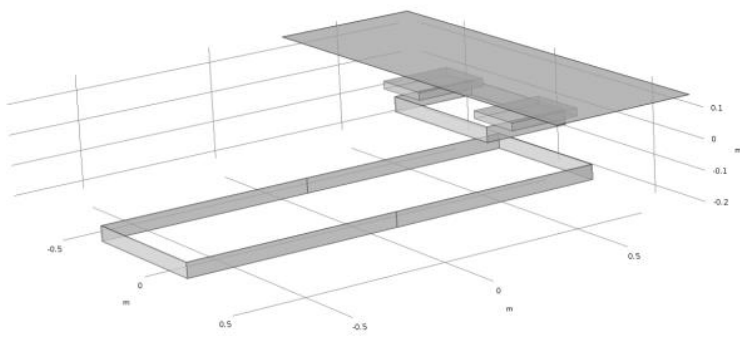

(b)

Fig. 6. Configuration with a misalignment of $0 \mathrm{~cm}$ (a) and $50 \mathrm{~cm}$ (b).

In this case, a total number of 100 samples are chosen (10 values for each of the two parameters). The same observation point is located (Fig.4). Fig. 7 and shows the plot of the flux density versus the two parameters. In this instance the reference level of $27 \mu \mathrm{T}$ is mainly and strongly dependent on the distance parameter.

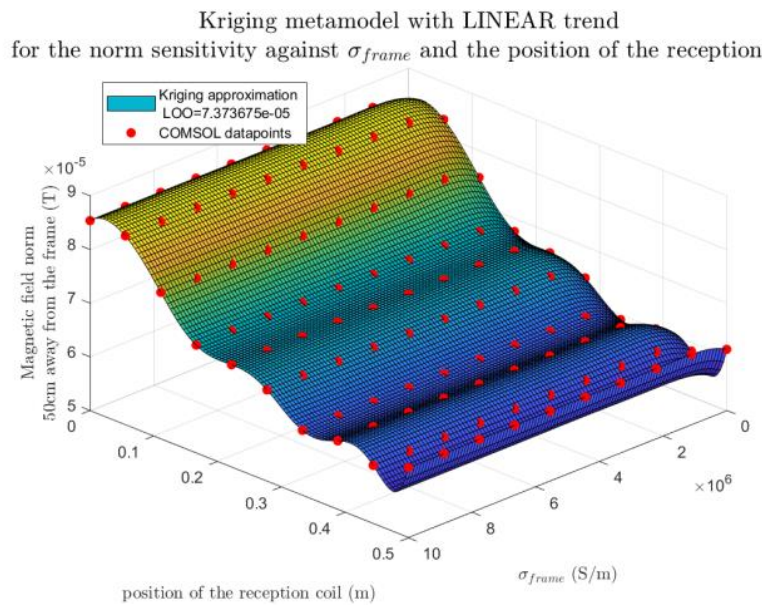

Fig. 7. 2D plot of the flux density for 100 sample data

Fig. 8 displays a 2D plot when the number of samples is reduced to $25(5 \times 5)$. The global behavior of the observable quantity is very well predicted from a few numbers of values.

Kriging metamodel with LINEAR trend

for the norm sensitivity against $\sigma_{\text {frame }}$ and the position of the reception coil

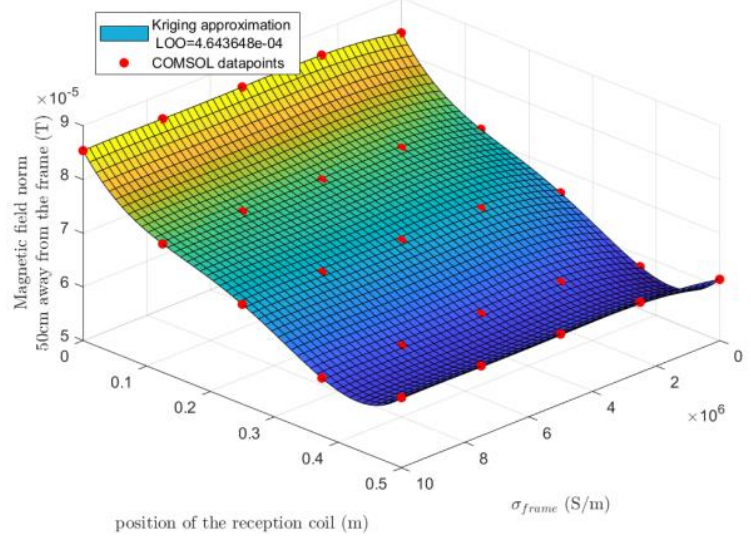

Fig. 8. 2D plot of the flux density for 25 sample data

\section{CONCLUSION}

Predictions of the radiated magnetic field have been obtained from a statistic approach and stochastic model (Kriging) in case of simplified but realistic wireless power transfer systems for electric vehicles. Kriging provides efficient meta-models to consider the uncertainties of different physical or geometrical parameters. Provided that the number of samples is sufficient, Kriging can be used as an efficient predictor to check if reference levels fit the guidelines for human exposure. The work is now extended to investigate more complex configurations taking into account the global structure of the vehicle and anatomical models of the human body.

\section{ACKNOWLEDGMENT}

The results here presented are developed in the framework of the 16ENG08 MICEV Project. The latter received funding from the EMPIR program co-financed by the Participating States and from the European Union's Horizon 2020 research and innovation program.

\section{REFERENCES}

[1] V. Cirimele, M. Diana, F. Freschi, M.Mitolo, "Inductive power transfer for automotive applications: state-of-the-art and future trends, IEEE Trans. on Industry Applications, Vol. 54, n5, 2018, pp 4069-, 2018.

[2] S. Park, "Evaluation of electromagnetic exposure during $85 \mathrm{kHz}$ wireless power transfer for electric vehicles", IEEE Trans. on Magnetics, Vol.53, $\mathrm{n}^{\circ} 1,2018$, paper 5100208.

[3] V. Cirimele, F. Freschi, L. Giaccone, L. Pichon, M. Repetto, "Human exposure assessment in dynamic inductive power transfer for automotive applications", IEEE Trans. on Magnetics, vol. 53, $\mathrm{n}^{\circ} 6$, 2017, paper 5000304 .

[4] ICNIRP Guidelines for Limiting Exposure to Time Varying Electric and Magnetic Fields (1Hz-100 KHz). Health Physics, 99, 2010, pp 818-836.

[5] G. Al Achkar, L. Pichon, N. Benjelloun, L. Daniel, "A broadband electromagnetic homogenization method for composite materials", IEEE Trans. on Magnetics, Vol. 54, n³, 9400304, 2018.

[6] D. Voyer, F. Musy, L. Nicolas, R. Perrussel, "Probabilistic methods applied to 2D electromagnetic numerical dosimetry", COMPEL, Vol. 27, $\mathrm{n}^{\circ} 3,2008$, pp. 651-667.

[7] J. Silly-Carette, D. Lautru, M-F. Wong, A. Gati, J. Wiart, V. Fouad Hanna, "Variability on the propagation of a plane wave using stochastic collocation methods in a bio electromagnetic application", IEEE Microwave and Wireless Components Letters, Vol. 19, $\mathrm{n}^{\circ} 4$, 2009 pp185 - 187.

[8] L. Makong, S. Rasm, L. Pichon, A. Kameni, A.Razek, "Comparison of stochastic approaches for human exposure assessment in inductive power transfer", IEEE CEFC (Conference on Electromagnetic Field Computation), Hangzhou, China, october 28-31th 2018.

[9] M. Feliziani, S. Cruciani, T. Campi, and F. Maradei, "Near field shielding of a wireless power transfer (WPT) current coil", Progress In Electromagnetics Research C, Vol. 77, 2017, pp 39-48.

[10] D. Kroese, T. Taimre, and Z. Botev. Handbook of Monte Carlo Methods. Wiley Series in Probability and Statistics, 2011.

[11] C. M. Ryan, "Computer expression for predicting shielding effectiveness for the low-frequency plane shield case", IEEE Trans. on Electromagnetic Compatibility, Vol. 9, n² 2, 1967, pp 83-94.

[12] S. Marelli, and B. Sudret, UQLab: A framework for uncertainty quantification in Matlab, Proc. 2nd Int. Conf. on Vulnerability, Risk Analysis and Management (ICVRAM2014), Liverpool, United Kingdom, 2014, 2554-2563. 